\title{
Hannah Arendt e as manifestações populares do Brasil e da Venezuela: compreensão fenomenológica
}

\author{
Hannah Arendt and the popular riots in Brazil and Venezuela: \\ reviewing of concepts and phenomenological comprehension
}

\author{
Gina Vidal Pompeu \\ Ana Carla Pinheiro Freitas \\ Alberto Dias de Souza
}

\section{Resumo}

No presente artigo, correlacionam-se os estudos de Hannah Arendt às manifestaçôes populares no Brasil e na Venezuela entre os anos de 2013 e 2014. Buscam-se subsídios para a reflexáo, sob o signo da compreensão: um diz respeito à hipótese teórica de que o poder tem sofrido mudanças importantes no sentido de sua degeneraçáo e o outro relaciona-se ao aspecto prático, por meio de variáveis econômicas inerentes ao desenvolvimento humano, que refletem o papel da economia no contexto em estudo. A compreensão fenomenológica das manifestaçóes populares permite ao intérprete-cidadáo, a capacidade de ter a si próprio como agente do poder.

\section{Palavras-chave}

Manifestaçôes Populares; Compreensão; Hannah Arendt.

\begin{abstract}
This article correlates the studies of Hannah Arendt to popular manifestations in Brazil and Venezuela between the years 2013 and 2014. The objective is to seek theoretical subsidies for reflection based upon the symbol of understanding: one objective relates to the theoretical hypothesis that the power has undergone major changes in the direction of its degeneration and, the other relates to the practical aspect, through economic variables inherent in human development that reflect the role of the economy in the context here examined. The phenomenological understanding of demonstrations allows the interpreter-citizen the ability to have himself as power agent.
\end{abstract}

\section{Keywords}

Popular Riots; Comprehension; Hannah Arendt. 
64 | Gina Vidal Pompeu, Ana Carla Pinheiro Freitas e Alberto Dias de Souza

\section{Introdução ${ }^{1}$}

Ao deparar com o contexto de constantes protestos ao redor do mundo nos últimos anos, um observador pode indagar-se acerca dos motivos que levam à ocorrência de tais eventos. Seus esforços de reflexão costumam variar desde a tentativa de alteridade até a verificaçáo de seu próprio entorno, com o ímpeto de identificar os elementos que caracterizam a inspiração dos acontecimentos. Com frequência, é possível delimitar as indagaçóes ao questionamento acerca do que se deve proteger.

Por intermédio do presente trabalho, dispóe-se a analisar as manifestaçóes populares que ocorreram no Brasil e na Venezuela entre os anos de 2013 e 2014. A razão de ser da identificação entre estes países reside na proximidade de motivos e de características gerais entre os protestos, que vão desde a insatisfação econômica até o pedido radical de mudanças políticas.

Para tanto, vale-se da perspectiva da teórica política Hannah Arendt (19061975), que, em sua obra, estudou eventos marcantes do século XX sob a ótica da compreensão fenomenológica, a qual é caracterizada pela valorização da postura do intérprete frente aos acontecimentos. Observa-se que, no âmbito da cidadania, cumpre ao ser humano o desempenho de ser partícipe do processo de escolhas e de decisôes políticas inerentes à realidade histórica de cada época. Nesse viés, o ser político é chamado, a cada momento, ao processo de reflexáo e de tomada de decisóes.

Apresentam-se, para reflexão, dois argumentos para se averiguar as razões das manifestaçóes populares: o primeiro referencia a hipótese, levantada por Arendt (2014), e, posteriormente, revisitada por Moisés Naim (2013) e Alessandro Baratta (2000), de que o poder tem sofrido candentes mudanças nos últimos anos, o que levou à sua degeneraçáo. Noutra vertente, com o escopo de entender os motivos da insatisfação popular, a pesquisa empírica explorou o exame das taxas de mortalidade infantil, pobreza e indigência, assim como as de distribuição da população economicamente ativa e consequente desemprego, no Brasil e na Venezuela. Revelouse que estas condiçóes impactam no descompasso entre crescimento econômico e desenvolvimento humano dos dois países.

A metodologia da abordagem é analítica, empírica e crítica. Leva em conta a análise de textos de autores que tratam sobre a América Latina em seu contexto atual,

\footnotetext{
Trabalho desenvolvido por membros do Centro de Estudos Latino-Americanos (CELA) e participantes do grupo de pesquisa "Relaçôes Econômicas, Políticas e Jurídicas na América Latina" do Conselho Nacional de Desenvolvimento Científico e Tecnológico (CNPq).
} 
e fixa-se no estudo da degeneraçáo do poder, a partir do conteúdo do ensaio Que é autoridade, de Hannah Arendt (2014). Posteriormente, por meio de verificaçáo empírica, diante da coleta de dados de sites oficiais, identifica a situação política e econômica para fundamentar opinião crítica sobre a matéria.

\section{O esforço fenomenológico de compreensão da realidade}

Não sáo recentes as tentativas da Filosofia em aliar seus preceitos teóricos com as manifestaçóes diversas da realidade. Os acontecimentos que marcaram o século $\mathrm{XX}$, com toda a sua complexidade, trouxeram um novo desafio para aqueles que se propóem a tarefa da reflexão. Assim, questiona-se como aliar a tradição do pensamento ocidental, conectado à racionalidade e à observaçáo segura dos eventos, à postura de choque e descrença que as guerras mundiais e os conflitos zonais incutiram nos espíritos.

Dentre os pensadores que se dedicaram a este esforço, destacam-se os escritos de Edmund Husserl e Martin Heidegger. Husserl é considerado o precursor de um formato de pensamento que passou a encarar o mundo real como algo que se constrói progressivamente no curso da experiência. Nesse contexto, é necessário que haja um observador consciente para que o evento posto sob análise tenha um sentido e seja apreensível. O próprio mundo é, pois, um fenômeno (BERNET, 2012).

Com Heidegger, essa noção ultrapassou os limites da filosofia pura e, com a mescla da poesia e de um sentido de renovação das noçóes de descobrimento do saber e a introdução do conceito de ontologia fundamental, passou-se a buscar a essência íntima do ser das coisas. A verdade do entendimento perpassava pela descoberta da verdade do Ser, o que só seria possível mediante a conscientização do Ser-no-Mundo, ou o Ser-lançado, o Dasein, categoria especial de consciência que corresponde à existência do homem.

A utilização da fenomenologia, tanto sob o viés de postura autorreferencial de consciência, quanto o de valorização da descoberta (ou o de desvelamento, para que se pratique a usual terminologia de Heidegger) da verdade do Ser, foi captada por Hannah Arendt (1993), que se valeu dela para iniciar uma categoria própria de reflexão, centrada na postura do observador frente aos fenômenos políticos de sua época.

\section{O sentido de compreender}

Não é possível dizer que Arendt buscou uma resposta à pergunta acerca da verdade do Ser, como Heidegger fizera. $\mathrm{O}$ que de fato a inspirou a questionar a 
realidade foi a perspectiva de paroxismo que a experiência totalitária deflagrou em todo o mundo, tanto sob a ótica das vítimas, quanto dos que se tornaram cônscios das atrocidades. André Duarte (2002) argumenta que a preocupação fundamental de Hannah Arendt (1993) é de ordem política, âmbito da existência que a Filosofia insistia em olvidar.

Veja-se que a tradição filosófica cede, a partir do platonismo, a um ímpeto de encarar a realidade de modo a encaixá-la em noçóes pré-fabricadas. Ao escrever $A$ República, Platáo aponta o que considerou a perfeiçáo para uma comunidade política. Sob outra perspectiva, constata-se que Arendt é uma pensadora da realidade visceral, que muitas vezes se encontra vilipendiada. Essa condição ocorre diante do olhar impassível de observadores incapazes de entender o que se desenlaça naquele momento.

A primeira conclusão possível desta forma de compreender a realidade representa a inclusão do intérprete na desconfortável posição de partícipe, assim carece reconhecer a si mesmo como parte fundamental do contexto que observa. Não se adotará mais a cândida postura, frequente entre pensadores da crise, de afastamento completo do objeto observado a fim de se montar um panorama descritivo. Ao contrário, faz-se necessário encarar-se como elemento integrante do real.

Esta postura é afirmada por Baratta (2000) ao analisar a perspectiva de crise dos Estados da América Latina frente às constantes tensóes entre o poder estatal e a violência. Em suas consideraçóes, a compreensão e enfrentamento do problema, categorias que se mostram indissociáveis, exigem uma alteraçáo significativa do ponto de vista do intérprete, que náo mais se enxergará apenas como vítima do processo de desencadeamento da violência, "sino también y sobre todo en cuanto actores corresponsables de la mistificación” (BARATTA, 2000, p. 197).

A segunda consideração que deflui do processo fenomenológico de compreensão reside na assertiva de que o evolver histórico guarda consigo possibilidades emancipatórias de entendimento da realidade contemporânea. Ao observar o entorno a partir da consciência própria que molda o fenômeno, o intérprete se abre a novas postulaçóes acerca da historicidade que lhe foi repassada. Duarte (2002, p. 115) afirma que o passado se torna uma fonte de possibilidades políticas que não se mostram fora da atualidade, e tampouco são modelos "heurísticos com os quais se pode confrontar e julgar o presente".

Nessa linha de pensamento, o ideal da compreensão possibilita, de um modo extremo, a reconciliaçáo do indivíduo com a sua própria realidade. Náo no sentido de 
disponibilizar um perdão salvífico, capaz de apagar ou desfazer o que foi feito, o que soa como tarefa irrealizável. $\mathrm{Na}$ medida em que, marcado pelo evolver histórico, torna-se processo em moto-perpétuo, compreender representa, para Arendt (1993, p. 39), "a maneira especificamente humana de estar vivo", pois todos os homens precisam religar-se com o mundo para quem são estranhos, condição adquirida das próprias singularidades.

\section{As manifestações populares no século XXI e o modelo virtual da Internet}

Vale salientar que a compreensão fenomenológica da realidade traz ao intérprete possibilidades emancipatórias no sentido de situá-lo como parte integrante do objeto cognoscível. Abre-lhe, igualmente, o horizonte de sentido para novas perspectivas históricas, que serão úteis para a apreensão dos eventos contemporâneos.

Nesse sentido, convém a exposição de elementos comuns às manifestaçóes populares. Não se pode assertar, após o advento das redes sociais de comunicação instantânea, que um movimento popular é desconhecido por várias partes do mundo, distantes em função da geografia. Ao contrário, a evolução da tecnologia aproximou as informaçóes ao ponto de ser possível afirmar que os eventos globais se tornaram compartilhados.

Castells (2013), ao discorrer sobre os movimentos de protesto que ocorreram em todo o planeta a partir de 2010, assevera que houve, na logística das manifestaçôes, a adoção de um modelo comum de atividades. Este, por sua vez, é centrado nas convocaçóes pela Internet, na constituição de redes no ciberespaço, e nos apelos pela ocupação dos espaços públicos com o intuito de pressionar os governos por mudanças. Entre os manifestantes, verificou-se rejeição contra o poder de mando do Estado, falta de aderência à ideologia político-partidária, congregaçáo de interesses entre as diversas classes sociais, tanto dentre os manifestantes ativos, quanto com os observadores, e, por fim, a simpatia ao movimento pela opiniáo pública internacional. A ambientação virtual, também, possibilita a exposição de imagens e de depoimentos que inspiram sentimentos

Estas circunstâncias permitem a conotação de que as manifestaçôes populares não são movimentos que acontecem com pessoas desconhecidas em algum local isolado ou exótico do globo. Ao contrário, o conhecimento dos fatos revela que o cidadão local é também cidadão global, detentor de direitos humanos. Diante do 
conhecimento dos fenômenos, ocorre a apreensão de sentido que corresponde à máxima intitulação da consciência de coletividade.

\section{Reflexões sobre causas prováveis}

O progresso tecnológico e industrial do século XX repercutiu em benesses para boa parte da população do planeta. Cumpre ressaltar, nesse contexto, que a América Latina, soçobrada por ditaduras militares durante parte do século, evoluiu por meio da participação popular para adotar o regime político democrático. Sabe-se que os impulsos democráticos iniciados a partir dos anos 1980 consolidaram-se em eleiçôes regulares e no fortalecimento das instituições, porém, resultam no século XXI em frustração e desconfiança com a democracia, haja vista que foi incapaz de exercitar controle social do poder público, conciliando liberdade econômica com igualdade social.

Diante da realidade sul-americana, superou-se uma corrente ideológica e doutrinária em vigor nos anos 1960 e 1970, no âmbito dos debates políticos no cenário norte-americano de então, a qual mencionava que os países ibéricos não possuíam autonomia suficiente para suportar outra organização política que não fosse o autoritarismo. A razão de ser desta situação residiria na ausência de individualismo, no sentido social, econômico e religioso do termo, dentre os habitantes e as instituiçóes locais. Havia, em razáo da falta de pensamento individualista, um despreparo generalizado para a democracia nos países ibéricos. Deste modo, surgia um ambiente fértil para as ditaduras de caráter fascista na Europa e o militarismo elitista no cone sul (O'DONNELL, 2011).

A democracia eleitoral vivenciada na América Latina não se fez acompanhar pela democratização econômica, o que provocou insatisfação popular diante da falta de efetivaçáo de direitos sociais. Nesse viés, constatava-se a presença de instituiçóes que reivindicavam políticas públicas inerentes ao exercício do bom Estado de governo. Entretanto, este contexto não se apresentou inteiramente hígido. De fato, frequentes denúncias de corrupção governamental, constantes violaçôes às constituiçóes nacionais, mormente no que se refere à efetivação de direitos sociais, bem como a existência de fraudes eleitorais e eleiçôes parlamentares de representatividade desproporcional grassaram o ambiente político de vários países latino-americanos (STRECK e MORAIS, 2014).

A partir do ano de 2013, Brasil e Venezuela passaram a sediar constante onda de protestos que canalizaram insatisfação generalizada com o status quo da política. Impulsionados tanto pelo sentimento genérico de descontentamento até a 
reivindicação de renúncia dos ocupantes do Poder Executivo. As massas populares têm demonstrado, por meio de ocupaçóes, concentraçóes, passeatas, piquetes e bloqueios de estradas, sua desaprovação contra a situação política vigente em ambos os Estados.

No Brasil, a insatisfação social principiou como um repúdio ao aumento das tarifas de transportes públicos. Contudo, esta problemática serviu apenas de "fagulha para atear um fogo que se alimentou de muitos outros combustíveis" (CARVALHO, 2014, p. 10). Logo estariam em foco as lutas pela reforma do sistema político como um todo, os anseios pelo encerramento dos gastos públicos nas obras de infraestrutura para eventos esportivos mundiais e os apelos de renúncia em desfavor da ocupante da Presidência da República, Dilma Rousseff, sucessora de Luís Inácio Lula da Silva, que representa a continuidade de uma facção política no poder desde 2002.

$\mathrm{Na}$ Venezuela, a eleição de Nicolás Maduro, também em 2013, e sua assunção ao poder no ano seguinte, bem como a forte retraçáo econômica causada pela queda do preço do petróleo, os saltos da inflaçáo e a violenta repressáo dos protestos oposicionistas, provocaram agitaçóes sociais variadas. Pagni $(2015, \mathrm{n} / \mathrm{p})$ denominou "mobilização permanente" a situação venezuelana de manifestaçóes sociais.

Lopez Maya (2014, p. 276) diagnostica que a participação popular venezuelana, que também pode ser entendida como "empoderamiento, poder popular, ciudadanía plena, democracia sustantiva" não expressa somente insatisfação genérica, mas genuína tentativa de "atrapar la idea de una democracia más dinámica y profunda, que recuperase el crecimiento económico perdido y cumpliese las promesas de justicia social, igualdad y ciudadanía". Nesse diapasão, ir às ruas e participar da política tornou-se quase um "instrumento-panacea en la superación de todos los males”.

Os pontos de convergência entre os contextos brasileiro e venezuelano indicam para a direção de que tanto o poder político quanto a economia são os itens nevrálgicos das altercaçóes e das manifestaçôes populares que ocorrem em ambos os países. A partir destas consideraçôes, faz-se uma ponderaçáo destes fatores, no seio da perspectiva da compreensão fenomenológica.

\section{A degeneração das estruturas de poder e de autoridade}

Ao refletir acerca da significação histórica do conceito de autoridade, Arendt (2014, p. 127) afirma que o século XX trouxe questôes que desafiaram as clássicas consideraçóes de autoridade no mundo moderno. Essa crise de poder é "política em 
sua origem e natureza", porquanto acompanha a condição do homem com a liberdade, conceito que, no pensamento da autora, é sinônimo do agir político.

Reitera-se que a liberdade é essencial à condição humana, este dado mostra-se consonante com as questóes contemporâneas, e não incide nos riscos inerentes ao estudo de autor específico relacionado às tentativas de encaixar em um dado pensamento ou corrente filosófica as questóes que não foram originalmente suscitadas pelo escritor. Veja-se ser corrente a noção de que o poder clássico, na contemporaneidade, está se degenerando.

Vale ressaltar a doutrina de Naim (2013), quando assevera que as mudanças ocorridas na geopolítica tradicional consolidada no fim do século XX, são questionadas por agentes de menor força. O fim da Segunda Guerra trouxe ao mundo a realidade das superpotências, cujo predomínio, após o fim da Guerra Fria, coube apenas aos Estados Unidos. Os norte-americanos, embora ainda ocupem a posição de destaque internacional, em razão da sua hegemonia militar, tecnológica, industrial e logística, não estão imunes à influência e aos direcionamentos de outros países e organizaçóes.

No diagnóstico do autor acima citado, o poder, entendido como a capacidade de conseguir com que outros façam ou deixem de fazer algo, está em franca mudança. As razões para esta transição são variadas, mas concentram-se em três pontos focais: o eixo da abundância de recursos, entendido como o "Mais"; a movimentação de pessoas e recursos de modo fluido, a qual configura o eixo da "Mobilidade"; e a mudança de expectativas e aspiraçōes, que personifica o eixo da "Mentalidade".

Em explicação fundamental, Naim (2013) enumera motivos que têm levado o poder a se degradar, e, dentre eles, destaca: as transformações consistentes no rápido crescimento econômico dos países pobres; os padróes e influxos migratórios; as mudanças na educação e mesmo nas tradiçóes culturais. A fragilidade do poder formal resulta no enfraquecimento dos Estados Nacionais na geografia mundial.

No mesmo sentido, Arendt frisara esta questão em meados do século XX. A crise do poder, em sua ótica, se espalhou até em áreas pré-políticas, como a criação dos filhos e a educação, nas quais a autoridade era aceita como "uma necessidade natural". O ímpeto do homem em seguir um formato de autoridade mostra-se propensão acalentada desde as fases da vida em que não está inserido na comunidade política. Assim, qualquer alteração que signifique mudança de poder ou de autoridade gera inquietação.

Faz-se necessário destacar que Arendt diferencia autoridade de poder. $\mathrm{O}$ poder é a habilidade humana de agir em concreto. Ele é grupal e apenas se manifesta se o 
grupo permanece unido. Se o grupo desaparece, também o poder se esvai. Já a autoridade pode ser transmitida ou investida, tanto em cargos quanto em postos hierárquicos, sejam de ordem estatal ou secular. Para que exista, é imprescindível o "reconhecimento inquestionável daqueles a quem se pede que obedeçam" (ARENDT, 2014, p. 60-64).

Cumpre salientar que poder e autoridade encontram-se em um contexto de crise, e as tentativas de trazê-las à tradicional e histórica força não se limitam à recuperação da legitimidade, seja ela grupal ou institucional. No intuito de superar a sua degeneração, os detentores do poder e da autoridade recorrem à violência.

No que se refere às manifestaçóes populares do Brasil e da Venezuela, o uso da violência tornou-se quase consequência lógica. No contexto brasileiro, os movimentos de junho de 2013, classificados por analistas como uma inédita forma de protesto pacífico, tornaram-se palcos de reaçóes extremas por parte das autoridades policiais. Carvalho (2014) asserta que a entrada de grupos minoritários intitulados black blocks, adeptos da violência, trouxeram ao ambiente de protestos o clima de balbúrdia que possibilitou o início das reprimendas policiais e que esta circunstância, por fim, afastou boa parte dos manifestantes.

A escalada da violência ocorrida no seio das manifestaçôes brasileiras foi uma das principais argumentaçôes em torno da inclusão de práticas comumente ligadas a protestos na conceituação de atos de terrorismo na recente Lei no 13.260 , de 16 de março de 2016. Os incisos II e III do $\$ 1^{\circ}$ do art. $2^{\circ}$, que previam os núcleos do tipo "incendiar, depredar, saquear, destruir ou explodir meios de transporte ou qualquer bem público ou privado", bem como "interferir, sabotar ou danificar sistemas de informática ou bancos de dados” foram vetados pela Presidência da República. O argumento utilizado para o veto foi a definição ampla e imprecisa que os tipos penais suscitavam. Pode-se dizer que risco fático era a possibilidade de atos criminosos serem relacionados a manifestaçóes populares gerais.

Já no caso venezuelano, a situaçấo constante de protestos levou o país a testemunhar onda intensa de violência, agravada pelo problema estrutural da segurança pública. Abusos são registrados tanto por parte do governo quanto por parte dos manifestantes, e estes coexistem com notícias de assassinatos na periferia de grandes centros urbanos. Scharfenberg (2014) registra que o saldo entre a violência decorrente das manifestaçôes políticas e as ocorrências exclusivamente policiais já permitem classificar a Venezuela como o segundo país mais perigoso do mundo. 
Nessa linha de pensamento, o contributo de Arendt para a compreensão das relaçóes entre poder, autoridade e violência é traço dicotômico entre estes conceitos, afirmando, em suma, que "a autoridade exclui a utilização de meios externos de coerção; onde a força é usada, a autoridade em si mesmo fracassou” (ARENDT, 2014, p. 129). Contudo, ela admite que, embora sejam distintos, poder e violência frequentemente aparecem juntos (ARENDT, 2014).

$\mathrm{O}$ fato de poder e violência estarem associados, por vezes, não permite, decerto, justificar a necessária coexistência. A lição fenomenológica pode ser aqui também aplicada, máxime no rompimento com a estrutura de continuidade que a visão platônica da história propicia. Há que se ter em mente a imprescindibilidade de se distinguir os conceitos, porquanto, justamente por existirem táo próximos no campo da existência pragmática, não se mostra saudável conceber que sejam similares. A consequência desta consideração seria tornar sinônimos conceitos que devem permanecer opostos.

Duarte (2014, p. 135) afirma que a superação desta aporia no pensamento de Arendt pode ser alcançada mediante a consideraçáo de que poder e violência coexistem em uma relação de proporcionalidade "em vista da qual quanto mais poder menos violência e quanto mais violência menos poder”. Esta visualização é útil porquanto traz equilíbrio às intrincadas relaçôes entre estes elementos no interior do Estado.

Em pensamento tangente, Baratta (2000) assevera que o papel do Estado, ainda que preponderante, vive um contexto de crise, em razão da perpetuaçáo da violência. $\mathrm{O}$ poder estatal, por mais abrangente que seja, náo conseguiu suprimir as manifestaçóes violentas no seio da sociedade.

Para situar suas assertivas, o autor traça panorama da história da filosofia no mundo ocidental, mais especificamente no eixo de compreensão da realidade. Houve, em sua interpretação das curvas de pensamento desde a Grécia até Marx e Freud, perpassando por Hegel e Kant, um deslocamento filosófico da "finitude para a infinitude". Frisa-se que este ponto, na perspectiva da ética, adquire uma face de autonomia. Nesse diapasão, na medida em que o ser humano é o referencial por excelência da ética, torna-se fundamental encará-la sob perspectiva antropológica.

O princípio antropológico da nova ética é diferente das noçôes de equilíbrio aristotélico. De fato, trata-se não mais de discutir a perspectiva de dominaçáo das paixôes e impulsos como o ímpeto da ética, mas a convivência entre o humano e o feroz. Fala-se, portanto, em autonomia racional. Todavia, mesmo diante desta alteração significativa na forma de se entender o entorno, a qual passa, 
essencialmente, pela consideração do "Outro", deve-se reconhecer a limitação do homem em compreender por completo a sua realidade.

A consciência de tal limitaçáo é a gênese do que Baratta (2000) refere ser o "pensamento débil". Com base em consideraçôes hauridas de Gianni Vattimo e Martin Heidegger, o autor apresenta como o pensamento débil prescinde de sistematizações teóricas universais. Esta reflexão se contenta com desconstruções parciais ou marginais, com "pequeñas historias" ou contrastes esfumaçados do crepúsculo, o que se aproxima da noção heideggeriana de antevisão, incompleta e inacabada, da condição do "ser-dos-entes".

$\mathrm{Na}$ perspectiva da incompletude, e diante de um meio para aceitá-la e com ela trabalhar, Baratta (2000) se debruça sobre a realidade de que a violência é ínsita tanto ao Estado quanto ao Direito. Assim, malgrado o esforço que se possa empreender, com todo o poder inerente a estas construções humanas, não será possível erradicar a violência por completo. O Estado é, neste contexto de reflexão, a dicotomia do "phármakon", palavra que, em grego antigo, pode ser traduzida tanto como "remédio" quanto "veneno".

Esta consideração é necessária para que o estudioso aprimore a visão da realidade. Trata-se do estabelecimento de critério para o enfrentamento da crise: a aceitaçáo da incompletude e imperfeiçáo do conceito de convivência plenamente harmônica. A segunda grande alteração referencial proposta pelo autor é a consideração de que o sujeito de que tratam as falas sobre a violência não são os "outros", mas "nós mesmos".

Nessa vertente, as consideraçôes entre o caminho intelectual traçado por Arendt acerca das alteraçôes de autoridade e poder e as formas de visualização desse contexto de crise permitem afirmar a utilidade da compreensão fenomenológica sugerida pela autora. $\mathrm{O}$ poder encontra-se em degeneração, e a violência parece surgir com mais intensidade que nunca. Entretanto, verifica-se aumento das potencialidades de atuação das massas ao se considerar que poder e violência existem no interior do Estado, e que o povo, enquanto integrante do fenômeno, não é somente vítima, mas protagonista da realidade. Contudo, não se deve crer que a compreensão das alteraçôes da sistemática do poder seja suficiente para o entendimento reflexivo acerca da dinâmica das manifestaçóes.

Em célebre passagem, contida nas descrições do capítulo XVII de O Príncipe, Maquiavel (2004), discorre acerca das vantagens de o governante ser cruel ou piedoso. Afirma que, em qualquer hipótese, o governante deverá abster-se de 
74 | Gina Vidal Pompeu, Ana Carla Pinheiro Freitas e Alberto Dias de Souza

aproveitar os bens alheios, "uma vez que os homens se esquecem mais rapidamente da morte do pai do que da perda do patrimônio" (MAQUIAVEL, 2004, p. 107).

A assertiva indica bem o papel que a preservaçáo da higidez econômica possui para as questóes políticas. $\mathrm{O}$ realismo que o pensamento de Maquiavel trouxe para a teoria política coaduna-se com as noçôes de compreensão fenomenológicas fixadas até o momento, pois leva em conta o papel do intérprete no entendimento dos fatos circundantes. Em outras palavras, se o patrimônio é preservado, há paz social.

\section{Os motivos econômicos}

Com o escopo de averiguar a ocorrência de boas práticas de governo nos dois países em comento, faz-se primordial explorar os dados diagnosticados por técnicos da Comissão Econômica para a América Latina e o Caribe (CEPAL). Nessa vertente, os gráficos a seguir são comparativos de variáveis socieconômicas brasileiras e venezuelanas extraídas dos bancos de dados da CEPAL ${ }^{2}$. A partir dos comentários aos pares estruturados, são realizadas consideraçóes acerca da influência de cada um dos dados nas manifestaçóes populares ocorridas em ambos os países na segunda década do século XXI.

2 Os gráficos apresentados neste artigo foram gerados a partir de ferramenta específica do sítio eletrônico da CEPAL. Os dados brasileiros estão disponíveis em <http://estadisticas.cepal.org/cepalstat/Perfil_Nacional_Social.html?pais=BRA\&idioma=spanish>. Acesso em 08 mai. 2016. Os dados da Venezuela foram obtidos em <http://estadisticas.cepal.org/cepalstat/Perfil_Nacional_Social.html?pais=VEN\&idioma=spanish>. Acesso em 08 mai. 2016. 
Gráfico 1 - Taxas de mortalidade infantil do Brasil (1951-2015)

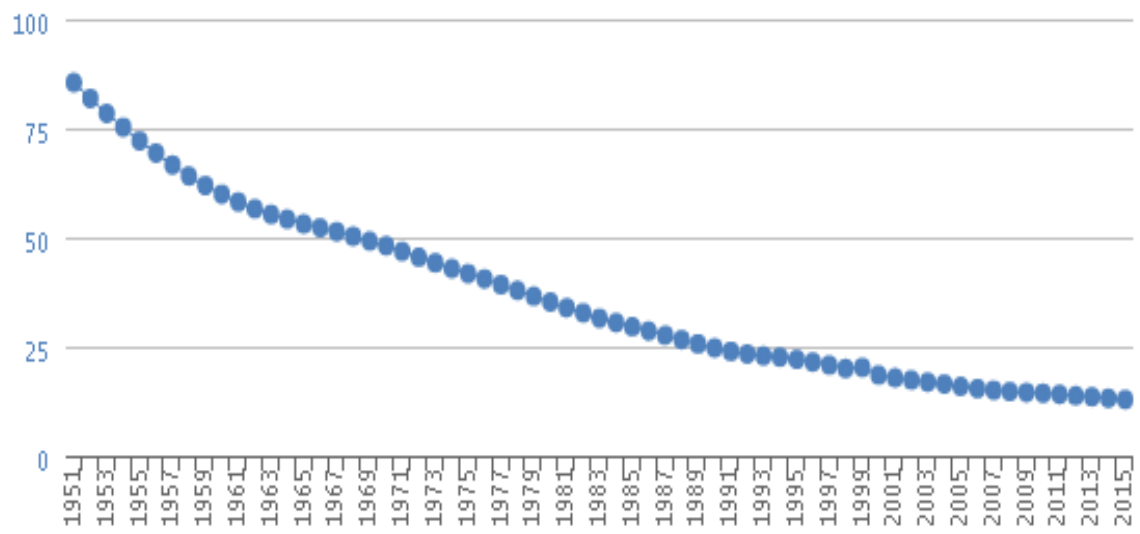

Fonte: Cepalstat, 1951-2015.

Gráfico 2 - Taxas de mortalidade infantil da Venezuela até 2015

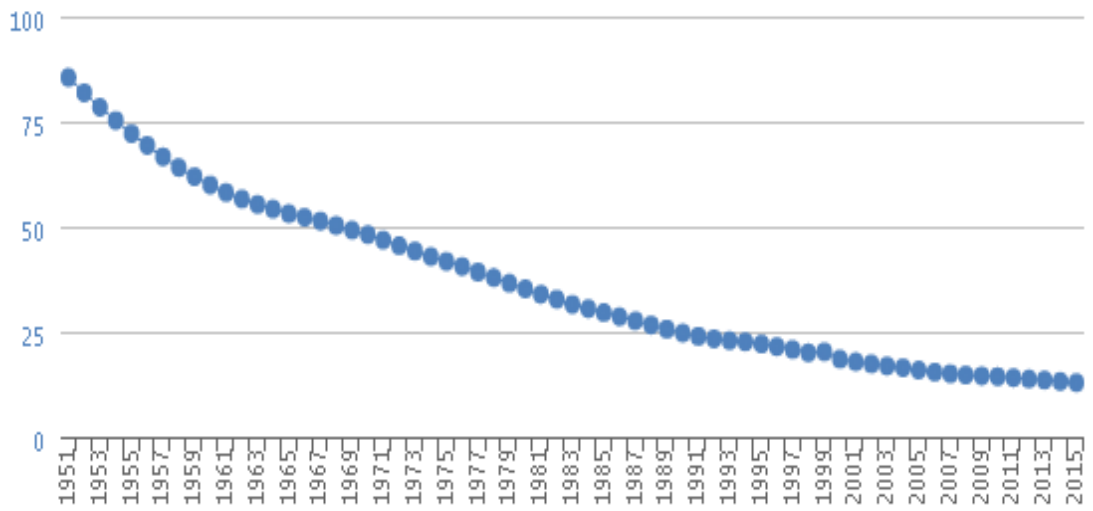

Fonte: Cepalstat, 1951-2015.

Pode-se constatar, por meio dos dados de ambos os gráficos inerentes ao Brasil e à Venezuela, no que se refere à mortalidade infantil, decréscimo constante das taxas. No caso brasileiro, entre os anos 2003 e 2015, que marcam os governos Lula e Dilma, houve sensível diminuição de mortos a cada 1000 nascimentos. No ano 2003, eram 22,5/1000, ao passo em que no último ano de aferição, a cifra caiu para 14,6/1000. Na Venezuela, entre os anos de 1999 e 2015, nos quais Hugo Chavez e 
76 | Gina Vidal Pompeu, Ana Carla Pinheiro Freitas e Alberto Dias de Souza

Nicolás Maduro governaram o país, verifica-se vertiginosa queda, de 20,2/1000 para $12,9 / 1000$.

Gráfico 3 - Taxas de pobreza e indigência no Brasil (1990-2014)

50

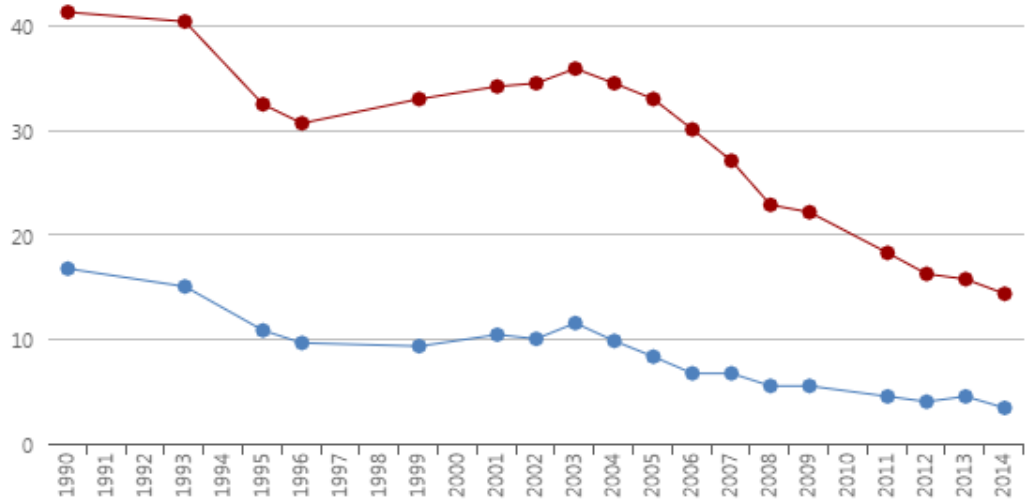

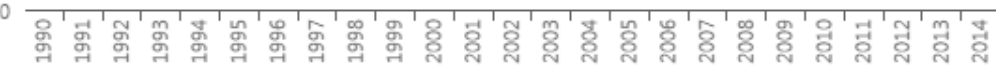

Indigencia $\mathbf{a}$ Pobreza

Fonte: Cepalstat, 1990-2014.

Gráfico 4 - Taxas de pobreza e indigência na Venezuela (1990-2014)

60

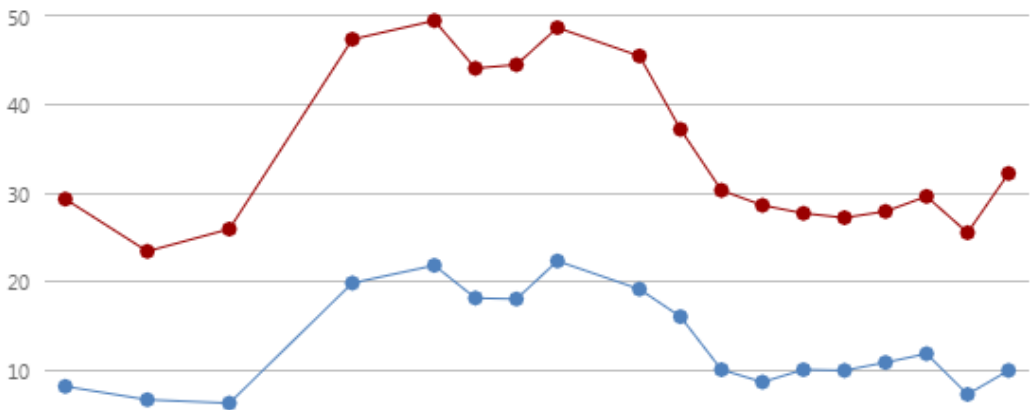

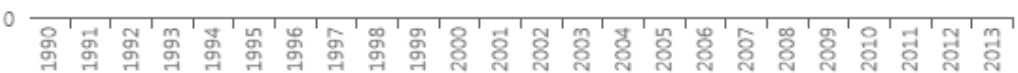

Indigencia $\mathbf{\square}$ Pobreza

Fonte: Cepalstat, 1990-2014. 
As taxas de pobreza e indigência em ambos os países seguiram padrão semelhante às quedas de mortalidade infantil. No Brasil, apenas em 2003 registrou-se um aumento significativo de ambos os índices, o qual foi seguido por queda constante. Em 2014, último ano da aferição, a pobreza atingia $14,3 \%$ da população, ao passo em que a indigência era relacionada a 3,4\%. Na Venezuela, entretanto, mesmo durante os anos em que a gestáo chavista estava no poder, ambos os índices sofreram aumento, e mesmo em 2013, último ano disponível, a pobreza e a indigência aumentaram.

Gráfico 5 - Distribuições da População Economicamente Ativa no Brasil (2014)

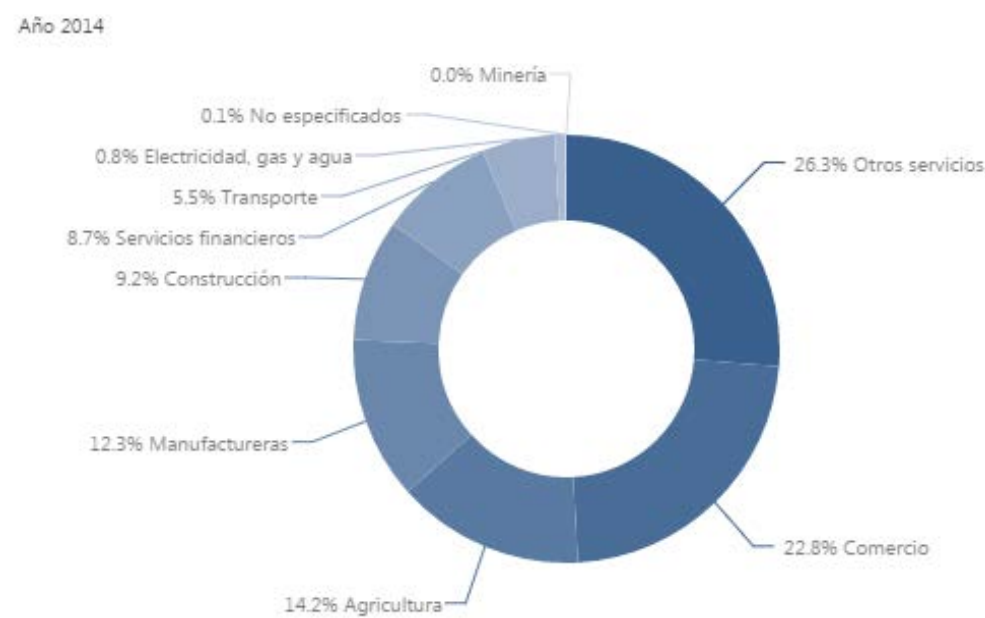

Fonte: Cepalstat, 2014. 
78 | Gina Vidal Pompeu, Ana Carla Pinheiro Freitas e Alberto Dias de Souza

Gráfico 6 - Distribuições da População Economicamente Ativa na Venezuela (2013) Año 2013

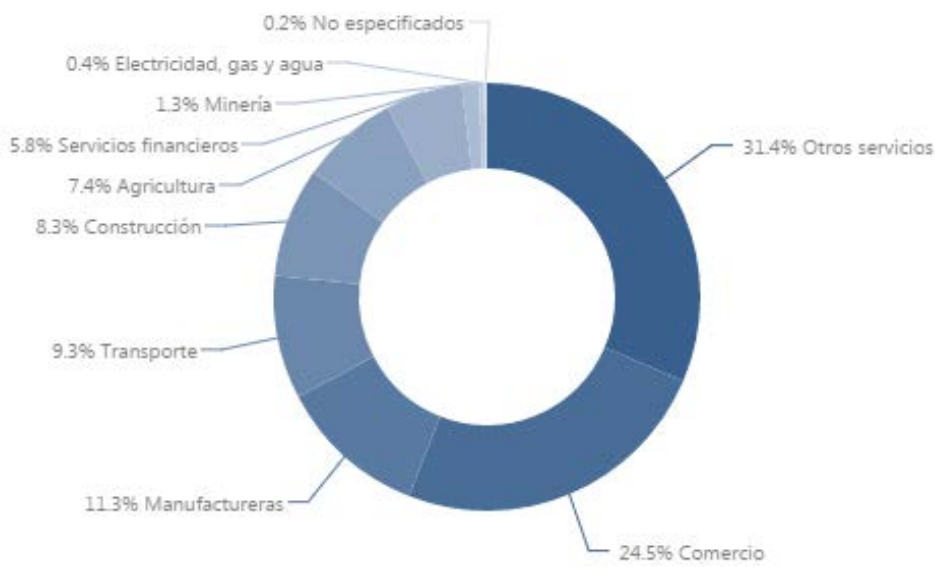

Fonte: Cepalstat, 2013

A População Economicamente Ativa (PEA) de ambos os países concentra a maior parte de sua força de trabalho no setor de comércio. A população que labora a partir da agricultura é maior no Brasil que na Venezuela.

Gráfico 7 - Taxas de desemprego no Brasil (1980-2015)

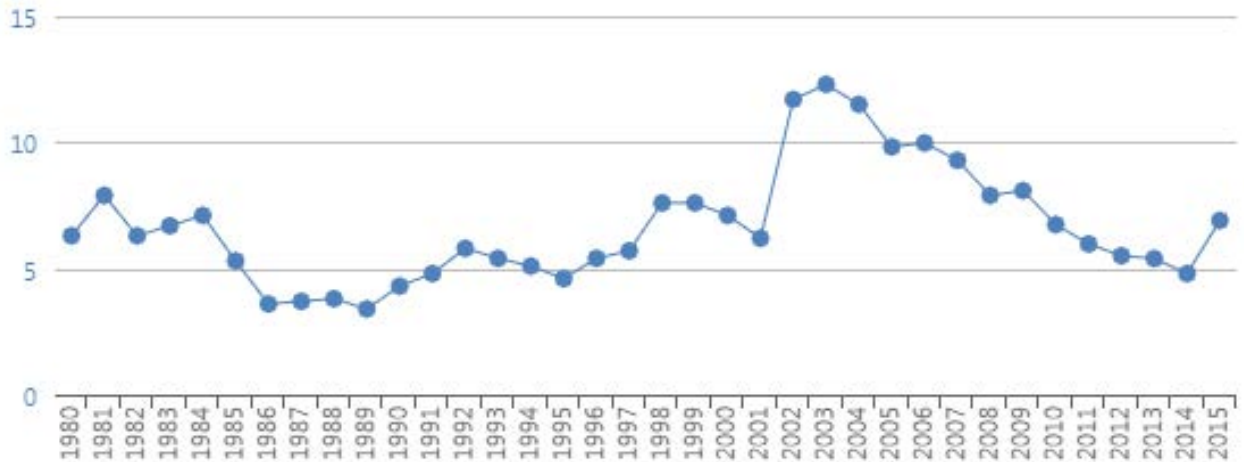

Fonte: Cepalstat, 1980-2015. 


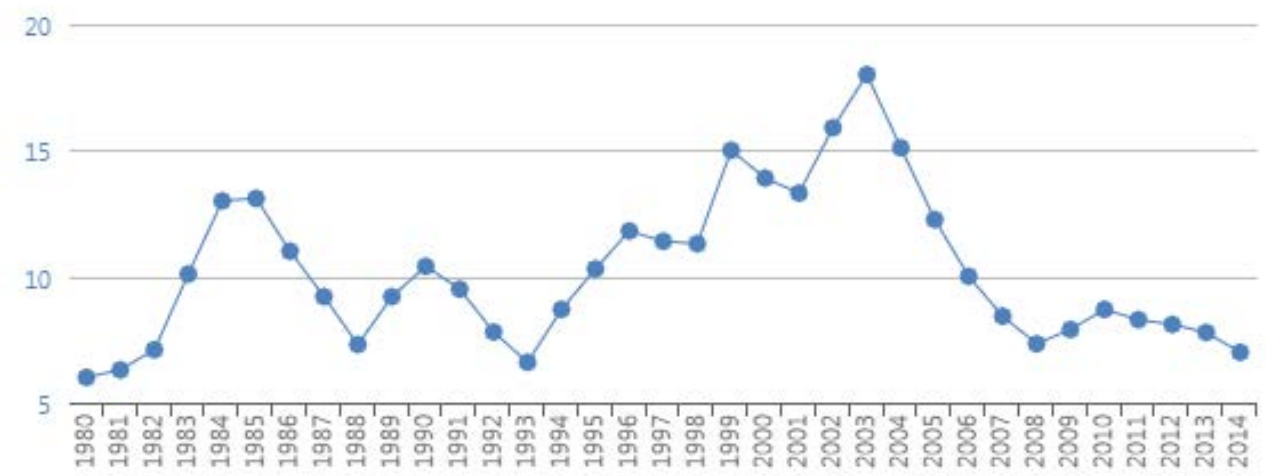

Fonte: Cepalstat, 1980-2015.

Por fim, as taxas de desemprego. No Brasil, os anos do governo Dilma registraram flutuaçóes constantes entre aumento e queda da empregabilidade, sendo certo que, no último período registrado, sobreveio o pior nível de emprego dos últimos seis anos. A Venezuela, de acordo com os dados coletados, registrou seu pico de desemprego em 2003, sendo aparente que, nos últimos quatro anos, este índice encontra-se em decréscimo.

A CEPAL adverte que os dados são obtidos a partir de cifras nacionais divulgadas pelos países. O quadro que se pretende demonstrar com estas consideraçóes é que não é possível atribuir somente às variáveis econômicas a tarefa de descrever a realidade. De fato, apenas a conjunção entre as consideraçóes políticas que analisam as questôes relativas ao poder e os vieses da economia é que podem fornecer subsídios para a compreensão fenomenológica.

\section{Conclusão}

Ao observador dos eventos, ao transeunte que, despercebido, tem seu olhar captado por uma notícia de jornal acerca das manifestaçóes, seja em mídia física ou televisiva, é provável o questionamento acerca dos motivos que levam algumas pessoas a se reunirem em prol de um ideal ou de uma mudança.

Ressalta-se, que a América Latina vivenciou, no final do século XX, o fortalecimento dos regimes democráticos, porém, a democratização eleitoral alcançada não repercutiu em democratização econômica. Revela-se que crescimento econômico também não significou desenvolvimento humano. $\mathrm{O}$ constitucionalismo 
brasileiro e venezuelano adotou a previsão de efetivaçáo de direitos sociais, elevandoos a direitos subjetivos, noutra vertente a ponderaçáo de dados identifica a frustração da população diante da carência de políticas públicas que efetivem sua condição de sujeito de direitos, fundamento das manifestaçóes.

A busca por efetivação de direitos, bem como a deterioração do poder, revela a noção de que os eventos têm se desenrolado não apenas em um ambiente distante, mas na própria vizinhança, e tampouco com outras pessoas distantes, mas consigo mesmo, consegue colocar o observador na posição de protagonista. Ele não é mais a vítima, mas assume igualmente a condição de agente.

A perspectiva fenomenológica é pródiga para conferir ao intérprete o "empoderamento" acerca de sua própria condição política. As manifestações que marcam o início do século XXI no Brasil e na Venezuela são a prova de que a todos é concedida a expressão. Nesse contexto, a violência, por tristeza da imperfeição humana, pode vir a acompanhar estes eventos. A degeneraçáo do poder, nos dias atuais, atinge todos os homens. A proposta da compreensão viceja no sentido de que o vácuo gerado seja preenchido pela novidade libertária que é a participação dos indivíduos na esfera política da realidade.

- Gina Vidal Pompeu é Doutora em Direito, pela Universidade Federal de Pernambuco. Atualmente é Professora e Coordenadora dos cursos de Mestrado e Doutorado em Direito na Universidade de Fortaleza (Unifor). E-mail: ginapompeu@unifor.br.

Ana Carla Pinheiro Freitas é Doutora em Direito, pela Pontificia Universidade Católica de São Paulo. Atualmente é Professora dos cursos de Mestrado e Doutorado em Direito na Unifor. E-mail: cpinheirofreitas@yahoo.com.br.

- Alberto Dias de Souza é Mestrando em Direito, pela Unifor. Atualmente é Professor na Faculdade Luciano Feijão. E-mail: diasalberto@hotmail.com. 


\section{Referências}

ARENDT, Hannah. Sobre a Violência. Trad. André de Macedo Duarte. 5. ed. Rio de Janeiro: Civilização Brasileira, 2014.

. Entre o passado e o futuro. Tradução de Mauro W. Barbosa. 7. ed. São Paulo: Perspectiva, 2014.

- A dignidade da política: ensaios e conferências. Organização de Antonio Abranches, tradução de Helena Martins e outros. Rio de Janeiro: Relume-Dumará, 1993.

BARATTA, Alessandro. El estado-mestizo y la ciudadanía plural. consideraciones sobre una teoría mundana dela alianza. In: GORSKI, Hector C. Silveira (org.). Identidades comunitarias y democracia. Madrid, Editorial Trotta, 2000. p. 185-210.

BERNET, Rodolf. Edmund Husserl. In: PRADEAU, Jean-François (org.). História da Filosofia. Rio de Janeiro: Editora PUC Rio/ Editora Vozes, 2012. cap. 41.

BRASIL. Lei no 13.260, de 16 de março de 2016. Regulamenta o disposto no inciso XLIII do art. $5^{\circ}$ da Constituição Federal, disciplinando o terrorismo, tratando de disposiçóes investigatórias e processuais e reformulando o conceito de organização terrorista; e altera as Leis nos 7.960, de 21 de dezembro de 1989, e 12.850, de 2 de agosto de 2013. Diário Oficial da República Federativa do Brasil, Poder Executivo, Brasília, DF, 16 mar. 2016. Disponível em <http://www.planalto.gov.br/ccivil_03/_Ato2015-2018/2016/Lei/L13260.htm>. Acesso em 08 mai. 2016.

CARVALHO, José Murilo de. Cidadania no Brasil: o longo caminho. 18 ed. Rio de Janeiro: Civilização Brasileira, 2014.

CASTELLS, Manuel. Redes de indignação e esperança: movimentos sociais na era da internet. Trad. Carlos Alberto Medeiros. Rio de Janeiro: Zahar, 2013.

CEPALSTAT - Bases de datos y publicaciones estadísticas de la Comisión Económica para América Latina y el Caribe. Perfil nacional socio-demografico de República Bolivariana de Venezuela. Disponível em <http://estadisticas.cepal.org/cepalstat/Perfil_Nacional_Social.html?pais=VEN\&idioma=spanish>. Acesso em 08 mai. 2016.

CEPALSTAT - Bases de datos y publicaciones estadísticas de la Comisión Económica para América Latina y el Caribe. Perfil nacional socio-demografico de Brasil. Disponível em $<$ http://estadisticas.cepal.org/cepalstat/Perfil_Nacional_Social.html?pais=BRA\&idioma=spanish >.

Acesso em 08 mai. 2016.

DUARTE, André. Hannah Arendt e a apropriação política de Heidegger. In: SOUZA, Ricardo Timm de; OLIVEIRA, Nythamar Fernandes de. Fenomenologia hoje II: significado e linguagem. Porto Alegre: EDIPUCRS, 2002. $\quad$ cap. 6.6 Disponível <https://books.google.com.br/books?id=rLQRe0yKE2MC\&lpg=PA103\&ots=9sLeoVCCSn\&dq=a\%2 0apropria\%C3\%A7\%C3\%A3o\%20pol\%C3\%ADtica\%20de\%20heidegger\%20hannah\%20arendt\&h l=pt-BR\&pg=PA103\#v=twopage\&q\&f=true >. Acesso em 05 mai. 2016.

Poder e violência no pensamento político de Hannah Arendt: uma reconsideração. Posfácio.

In: ARENDT, Hannah. Sobre a Violência. Trad. André de Macedo Duarte. 5. ed. Rio de Janeiro: Civilização Brasileira, 2014. p. 131-167.

LÓPEZ MAYA, Margarita. Venezuela: de la democracia participativa al Estado comunal. In: ZOVATTO, Daniel; WELP, Yanina; LISSIDINI, Alicia. Democracias en Movimiento: mecanismos de 
82 | Gina Vidal Pompeu, Ana Carla Pinheiro Freitas e Alberto Dias de Souza

democracia directa y participativa en América Latina. Ciudad de Mexico: Instituto de Investigaciones Jurídicas de la Universidad Nacional Autónoma de México, 2014. cap. 9. Disponível em <http://www.idea.int/es/publications/democracies-on-the-move/index.cfm>. Acesso em 05 mai. 2016. MAQUIAVEL, Nicolau. O Príncipe e Escritos Políticos. Consultoria de Carlos Estevam Martins. São Paulo: Editora Nova Cultural, 2004.

NAIM, Moisés. O fim do poder: nas salas da diretoria ou nos campos de batalha, em Igrejas ou Estados, por que estar no poder não é mais o que costumava ser? Trad. Luis Reyes Gil. São Paulo: LeYa, 2013.

O'DONNELL, Guilhermo. Democracia, agência e estado: teoria com intenção comparativa. Trad. Vera Joscelyn. São Paulo: Paz e Terra, 2011.

PAGNI, Carlos. Mobilizaçáo permanente na América Latina: o poder sindical murcha na América Latina e regiấo assiste a uma onda de protestos que exprimem a rejeição global aos que mandam. El País Brasil. Brasília, 31 ago 2015. Disponível em <http://brasil.elpais.com/brasil/2015/08/28/internacional/1440761763_909966.html>. Acesso em 16 abr. 2016.

PLATÃO. A república. Trad. Pietro Nassetti. 3. Ed. São Paulo: Martin Claret, 2015.

STRECK, Lenio Luíz; MORAIS, José Luís Bolzan de. Ciência Política e Teoria do Estado. 8. ed., revista e atualizada. Porto Alegre: Livraria do Advogado Editora, 2014.

SCHARFENBERG, Ewald. Venezuela é o segundo país mais perigoso do mundo. El País Brasil.

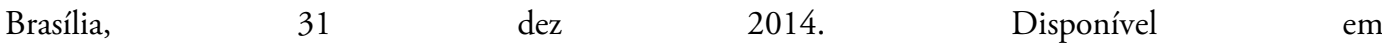
<http://brasil.elpais.com/brasil/2014/12/30/internacional/1419976892_348730.html>. Acesso em 09 mai. 2016. 